\title{
PENGARUH PEMBELAJARAN PROBLEM BASED INSTRUCTION TERHADAP KEMAMPUAN BERPIKIR KRITIS MAHASISWA PROGRAM STUDI PENDIDIKAN BIOLOGI FKIP UMB
}

\author{
Santoso ${ }^{1 *}$, Meti Herlina ${ }^{1}$ \\ ${ }^{1}$ Fakultas Keguruan dan Ilmu Pendidikan Universitas Muhammadiyah Bengkulu \\ Email: metyalina@umb.ac.id
}

\begin{abstract}
Abstrak
Penelitian ini bertujuan untuk mengetahui pengaruh model pembelajaran PBI (Problem Based Instruction) terhadap kemampuan berpikir kritis mahasiswa Pada Mata Kuliah Ekologi Hewan di Program studi Pendidikan Biologi FKIP UMB. penelitian ini merupakan penelitian Quasi eksperimen dengan menggunakan rancangan Randomized Prettes postes Control Group Design. Populasi penelitian ini adalah mahasiswa semester VII A dan VII C Prodi Pendidikan Biologi FKIP UMB. Penelitian dilaksanakan pada bulan Januari-Februari 2018. Analisis data dalam penelitian menggunakan uji Normalitas, uji Homogenitas dan uji-t dengan menggunakan program SPSS 22. Berdasarkan hasil penelitian diperoleh rata-rata nilai posttest pada kelas eksperimen yaitu 78. Hasil uji-t kemampuan berpikir kritis siswa memiliki nilai berbeda yaitu 0,000, $T_{\text {hitung }} 4.083$ dan $T_{\text {tabel }} 2.00$ maka $\mathrm{T}_{\text {hitung }}>\mathrm{T}_{\text {tabel }}(4.082>2.00)$, jadi $\mathrm{H}_{0}$ diterima dan $\mathrm{H}_{1}$ ditolak. Hasil penelitian menunjukan adanya pengaruh model pembelajaran berbasis PBI (Problem Based Instruction) terhadap kemampuan berpikir mahasiswa program studi FKIP UMB.
\end{abstract}

Kata Kunci : : Problem Base Instruction, Kemampuan Berpikir Kritis

\begin{abstract}
This study aims to determine the effect of PBI (Problem Based Instruction) learning modelon students' critical thinking skills at the Animal Ecology Course. This research is a quasi-experimental study using design of the Random Pretest Post-group design control. Research population is students at VII A and VII C of Biology Education Study Program FKIP UMB. This study was conducted in January-February 2018. The data was analysed through normality, homogeneity and t-test using SPSS 22. Results of the study show the average posttest value in the experimental class is 78 . Result of ttest critical thinking skills Problem Based Instruction (PBI) have different values of ( $p$-value $<0.0001, T$ count $>\mathrm{T}$ table which is 4,082>2.00). The results showed that there was an influence of PBI (Problem Based Instruction) based learning model on the thinking ability of FKIP UMB study program students.
\end{abstract}

Keywords : Problem Base Instruction, Critical Thinking Ability

\section{PENDAHULUAN}

Perkembangan ilmu pengetahuan dan teknologi akan membawa manusia ke era persaingan global yang semakin pesat. Kenyataan tersebut menjadi tantangan dalam dunia pendidikan. Pendidikan yang mampu mendukung manusia dalam persaingan global adalah pendidikan yang mengembangkan potensi anak didik. Pengembangan potensi anak didik tidak terlepas dari proses pembelajaran yang dapat mengembangkan keterampilan sains dan kemampuan berpikir anak didik (Pratiwi, 2012).

Menurut Mudyahardjo (2010) pendidikan adalah segala pengalaman belajar yang berlangsung dalam segala lingkungan dan sepanjang hidup. Pendidikan adalah segala situasi hidup yang mempengaruhi pertumbuhan individu. Menurut Anwar (2010) pengaruh pendidikan dalam jiwa seseorang adalah sebagai pendorong kemampuan untuk berkembang, sedangkan pendorong 
utamanya adalah potensi berupa bakat dan pengalamannya.

Era globalisasi merupakan tantangan bagi bangsa Indonesia khususnya dunia pendidikan. Dunia pendidikan dituntut mempersiapkan sumberdaya manusia yang kompeten agar mampu bersaing dalam pasar kerja global (Sumarni, dkk 2009). Peningkatan kualitas pendidikan di Indonesia selalu menjadi permasalahan penting dalam dunia pendidikan. Kualitas pendidikan selalu dikaitkan dengan pencapaian prestasi belajar yang diperoleh siswa dari hasil nilai ujian tiap semesternya. Kualitas pendidikan tidak dapat terlepas dari kualitas proses belajar yang dilakukan oleh guru dan dosen (Yuliana, 2013).

Salah satu masalah yang dihadapi dunia pendidikan kita adalah lemahnya proses pembelajaran. Mata pelajaran sains kurang dapat mengembangkan kemampuan berpikir kritis dan sistematis anak. Hal ini karena anak kurang didorong mengembangkan kemampuan berpikir dalam proses pembelajaran. Proses pembelajaran di dalam kelas diarahkan kepada kemampuan anak untuk menghafal informasi. Otak anak dipaksa mengingat dan menimbun informasi tanpa upaya untuk menghubungkannya dengan kehidupan sehari-hari. Dampak dari pola pembelajaran sepeti itu anak tidak memahami dan menguasai konsep yang diajarkan. Rendahnya penguasaan konsep sains disebabkan oleh pola pikir yang rendah pada pembentukan sistem konseptual (Jalaludin, 2009).

Berpikir kritis adalah berpikir logis dan reflektif uang dipusatkan pada keputusan apa yang diyakini atau dikerjakan (Ennis, 1985). Kemampuan berpikir kritis dapat diukur dari jenis soal yang menuntut keterampilan berpikir tingkat tinggi. Namun soal berpikir kritis yang dibuat oleh guru di Indonesia memiliki tingkat kerumitan rendah $(57 \%)$, sedang $(40 \%)$, tinggi (3\%) (Irwandi, 2016). Permasalahan ini memberikan dampak terhadap berpikir kritis siswa Indonesia, sehingga mereka tidak terbiasa menganalisis soal berpikir tingkat tinggi. Akibatnya hal tersebut tidak dapat mengakomodasi kemampuan siswa untuk mengembangkan kemampuan berpikir kritisnya.

Kemampuan berpikir kritis belum menjadi tuntutan uatama dalam pendidikan di Indonesia. Sebaliknya, keterampilan berpikir kritis di negara maju justru dijadikan dasar meningkatkan mutu pendidikan sains. Kebiasaan berpikir kritis pada anak akan menumbuhkan rasa ingin tahu, kemampuan berpikir tingkat tinggi dan membentuk kemampuan kerja sama (Rusyana, 2011).

Kondisi di perguruan tinggi juga tidak jauh berbeda. Mahasiswa hanya menghapal konsep tanpa mengembangkan secara mandiri. Konsep merupakan suatu hal yang penting, namun bagaimana konsep itu ditemukan sendiri oleh mahasiswa juga hal yang tidak kalah penting. Pentingnya penguasaan konsep dalam proses belajar mengajar sangat mempengaruhi sikap, keputusan dan cara memecahkan masalah (Trianto, 2011).

Menurut Puspita, dkk (2014) pembelajaran masih sering menggunakan metode atau model pembelajaran yang tidak sesuai dengan karakteristik materi. Mahasiswa juga kurang dilibatkan dalam pembelajaran yang memberi pengalaman langsung melalui pemecahan masalah sehingga mahasiswa tidak terbiasa menemukan konsep pelajaran secara mandiri. Model pembelajaran yang digunakan seharusnya sesuai dengan karakteristik materi pelajaran dan diarahkan pada proses pembelajaran yang berpusat pada mahasiswa (learned centered) sehingga prestasi belajar mahasiswa dapat meningkat.

Model pembelajaran Problem Based Instruction digunakan untuk 
mengembangkan kreatifitas mahasiswa baik individu maupun kelompok. Model pembelajaran ini dirancang agar mahasiswa mampu memecahkan masalah pembelajaran yang ada, selain itu membantu pembagian tanggung jawab mahasiswa mengikuti pembelajaran dan berorientasi menuju pembentukan manusia sosial.

\section{METODE}

Penelitian ini merupakan jenis penelitian Kuasi-Eksperimen, untuk mengetahui pengaruh model Problem Based Instruction (PBI) terhadap penguasaan konsep dan kemampuan berpikir kritis mahasiswa. Desain yang digunakan dalam penelitian ini adalah pretest-posttest design, yang dibagi menjadi dua kelompok yaitu kelompok pembelajaran $\mathrm{PBI}\left(\mathrm{X}_{1}\right)$ dan kelompok kontrol yang diberikan pengajaran konvensional dengan metode ceramah dan tanya jawab. Kedua kelompok diberi pretes $\left(\mathrm{O}_{1}\right)$ maupun Posttest yang sama $\left(\mathrm{O}_{2}\right)$ berupa pengetahuan tentang ekologi Hewan.

Populasi dalam penelitian ini adalah seluruh mahasiswa program studi Pendidikan Biologi FKIP Universitas Muhammadiyah Bengkulu (UMB) semester VI yang berjumlah 3 kelas, yaitul VIA dan VI C. Instrumen penelitian ini berupa RPS, LKM, dan soal berpikir kritis. Sebelum proses pembelajaran, mahasiswa diberi tes awal (pretest) yang sama antara kelas kontrol dan eksperimen mengenai materi biogeokimia di semester VII A dan VII C. Hasil tes ini bertujuan untuk mengetahui kemampuan awal mahasiswa. Setelah tes awal (Pretest) dilaksanakan, dosen memberikan materi pembelajaran. Pembelajaran kelas VIIA menggunakan model konvensional, sedangkan kelas VII C menggunakan model Problem Based Instruction. Setelah pembelajaran selesai, kedua kelas diberikan test akhir (Posttest) yang sama untuk mengetahui hasil belajar setelah mendapat pembelajaran dengan menggunakan model Problem Based Instruction (PBI) dan model konvensional.

Nilai pretest dan posttest yang diperoleh selanjutnya diuji dengan Uji t. Sebelum dilakukan Uji $t$, data terlebih dahulu diuji prasyarat yaitu uji normalitas dan uji homogenitas. Pengolahan data menggunakan SPSS versi 22.0.

\section{HASIL DAN PEMBAHASAN}

Setelah dilakukan pembelajaran, baik dengan menggunakan model PBI dan yang tidak menggunakan model PBI, hasil posttest dapat dilihat pada Tabel 1.

Tabel 1. Hasil Skor Posttest Berpikir Kritis

\begin{tabular}{lll}
\hline \multirow{2}{*}{ Perhitungan } & \multicolumn{2}{c}{ Kelas } \\
\cline { 2 - 3 } & Eksperimen & Kontrol \\
\hline Jumlah Skor & 2438 & 2205 \\
Skor Tertinggi & 92 & 85 \\
Skor terendah & 61 & 50 \\
Rata-Rata & 78,75 & 69,65 \\
\hline
\end{tabular}

Berdasarkan hasil pengukuran Posttest diperoleh rata-rata mahasiswa di kelas eksperimen yakni 78.75 dan untuk kelas kontrol 69.65. Hasil uji normalitas menggunakan Kolmogrov-Smirnov menunjukkan data skor Posttest terdistribusi normal, dapat dilihat pada Tabel 2.

Tabel 2. Uji Normalitas Skor Posttest Berpikir Kritis

One-Sample Kolmogorov-Smirnov Test Nilai_PBI

$\mathrm{N}$ 28

Test Statistic , 129

Asymp. Sig. (2-tailed) , $200^{c, d}$

Uji homogenitas menggunakan Levene menunjukkan bahwa skor post test dengan ini model pembelajaran PBI memiliki varian yang homogeny, dapat dilihat pada Tabel 3 
Tabel 3. Uji Homogenitas Skor Postes Berpikir Kritis

\begin{tabular}{|c|c|c|c|}
\hline & \multicolumn{3}{|c|}{$\begin{array}{c}\text { Test of Homogeneity of } \\
\text { Variances }\end{array}$} \\
\hline & \multicolumn{3}{|c|}{ Eksperimen } \\
\hline $\begin{array}{l}\text { Kemampuan } \\
\text { berpikir }\end{array}$ & $\begin{array}{l}\text { Levene } \\
\text { Statistic }\end{array}$ & $\mathrm{df1} \quad \mathrm{df2}$ & Sig. \\
\hline Kritis & 0.4 & 61 & .962 \\
\hline
\end{tabular}

Setelah diketahui bahwa data Posttest kemampuan berpikir kritis mahasiswa berdistribusi normal dan homogen maka untuk melihat signifikansi pengaruh pembelajaran Model Problem Based Instruction (PBI) terhadap kemampuan berpikir kritis dilakukan uji t (uji hipotesis). Hasil uji test skor posttest keterampilan berpikir kritis pada kelas eksperimen dan kelas kontrol dapat dilihat pada Tabel 4.

Table 4. Uji t Skor Posttest Berpikir Kritis Pada Kelas Eksperimen Dan Kontrol

\begin{tabular}{lccc}
\hline & & \multicolumn{2}{c}{ Eksperimen } \\
\cline { 3 - 4 } & & $\begin{array}{l}\text { Equal } \\
\text { variances } \\
\text { assumed }\end{array}$ & $\begin{array}{l}\text { Equal } \\
\text { variances } \\
\text { not } \\
\text { assumed }\end{array}$ \\
\hline $\begin{array}{l}\text { Levene's } \\
\text { Test for }\end{array}$ & $\mathrm{F}$ & .004 & \\
$\begin{array}{l}\text { Equality } \\
\text { of }\end{array}$ & Sig. & .952 & \\
Variances & $\mathrm{T}$ & 4.082 & 5.924 \\
& $\mathrm{Df}$ & 61 & 56.073 \\
& Sig. (2- & .000 & .000 \\
& tailed) & & \\
\hline
\end{tabular}

Berdasarkan Tabel 4 di atas dapat dilihat bahwa hasil uji $t$ kemampuan berpikir kritis mahasiswa pada kelas eksperimen dan kelas konvensional memiliki nilai yang berbeda yaitu 0.000 , $\mathrm{T}_{\text {hitung }} 4.082$ dan $\mathrm{t}_{\text {tabel }}$ 2,00 maka $\mathrm{t}_{\text {hitung }}$ $>t_{\text {tabel }}(4.082>2.00)$ jadi $\mathrm{H}_{0}$ diterima dan $\mathrm{H}_{\mathrm{l}}$ ditolak. Artinya terdapat pengaruh penggunaan model Problem Based Instruction terhadap kemampuan berpikir kritis mahasiswa di Program Studi pendidikan Biologi FKIP UMB.
Berdasarkan hasil penelitian dapat dinyatakan bahwa terdapat pengaruh model pembelajaran $\mathrm{PBI}$ (Problem Based Instruction) terhadap kemampuan berpikir kritis mahasiwa pada mata kuliah Ekologi Hewan di Program Studi Pendidikan Biologi FKIP UMB. Hasil ini didukung oleh Herlina (2014) yang menunjukkan bahwa model pembelajaran $\mathrm{PBI}$ juga efektif meningkatan kemampuan berpikir kritis mahasiswa pada matakuliah fisiologi tumbuhan di Program Studi Pendidikan Biologi UMB.

Jika dilihat dari hasil posttest skor rata-rata pada kelas eksperimen lebih tinggi yakni sebesar 78,75 dan kelas kontrol lebih rendah yakni 69,65 . Hal ini dikarenakan proses pembelajaran pada kelas eksperimen menggunakan model Problem Based Instruction yang mampu mengembangkan kemampuan berpikir kritis mahasiswa. Selain itu model PBI mampu melatih siswa untuk belajar mandiri dalam kelompok dan saling berdiskusi membahas materi. Dosen hanya berperan sebagai fasilitator sehingga siswa lebih dituntut aktif dalam mencari konsep. Hal ini sesuai dengan pendapat Trianto (2011) yang menyatakan bahwa model PBI membantu mahasiswa aktif dalam pengembangkan inkuiri sehingga mampu menemukan konsep yang mengarah kepada penguasaan konsep.

Selain itu, model pembelajaran Problem Based Instruction adalah pembelajaran berbasis masalah yang mampu memberikan kesempatan bagii untuk mengembangkan proses berpikir tingkat tinggi. Mahasiswa diberikan permasalahan kehidupan nyata yang mendorong mereka untuk mempunyai pengalaman dalam melakukan penyelidikan, membuat hepotesis, dan menarik kesimpulan dari suatu permasalahan yang ada. Hal ini sejalan dengan Redhan (2003) yang menyatakan 
bahwa strategi pemecahan masalah dapat mengembangkan keterampilan berpikir kritis dan kemampuan mahasiswa dalam mengadaptasi situasii baru. Peserta didik akan memperoleh informasi dan penemuan-penemuan yang diperoleh sendiri dari pengalaman belajar yang mereka lakukan, baik pada aspek kecepatan memahami pelajaran dan hasil belajar mahasiswa, artinya tidak semua metode dapat digunakan dalam setiap pokok bahasan materi.

Model pembelajaran PBI menuntut mahasiswa untuk aktif bekerjasama dalam kelompok dan saling memotivasi mengerjakan LKM. Mahasiswa saling berdiskusi untuk memecahkan permasalahan yang telah diberikan sehingga mampu menemukan kosep yang tepat dan mengambil sebuah keputusan dalam pemecahan masalah. Hal ini berdampak pada pengembangan kemampuan berpikir kritis. Hal ini dikarenakan model PBI memiliki karakteristik kolaborasi untuk membentuk kelompok kecil, bekerjasama untuk bertukar pikiran dan saling memotivasi untuk mengembangakan keterampilan sosial dan berpikir tingkat tinggi (Trianto, 2011).

Sementara itu rendahnya hasil belajar pada kelas kontrol disebabkan oleh proses pembelajaran yang masih berpusat pada dosen atau Teacher Center Learning. Mahasiswa hanya mendengarkan dan mendapat transferan informasi dan konsep, sehingga mahasiswa tidak mampu menemukan konsep dan memecahkan masalah secara mandiri. Hal ini berdampak pada kurangnya penguasaan konsep dan pengembangan kemampuan berpikir tingkat tinggi.

Pendapat ini sejalan dengan Gallow (2000) yang menyatakan bahwa pendekatan pembelajaran yang berpusat pada guru, sudah dianggap tradisional dan perlu diubah. Pendekatan yang berpusat pada guru hanya bersifat penekanan pada peliputan dan penyebaran materi, sementara mahasiswa kurang dituntut untuk lebih mandiri dan aktif. Pendekatan yang berpusat pada guru sudah tidak cocok untuk era pengetahuan saat ini.

Selain itu pada model pembelajaran konvensional, mahasiswa hanya dituntut untuk melihat mendengarkan, menghafal, dan memahami kosep yang disampaikan oleh dosen. Model ini tidak memberikaan pengalaman belajar yang mampu mengembangkan keterampilan berpikir kritis hingga siswa cenderung pasif. Yamin (2011) menyatakan bahwa pembelajaran konvensional lebih mengutamakan daya ingat dan daya hapal.

\section{DAFTAR PUSTAKA}

Anwar, M. 2015. Filsafat Pendidikan. Jakarta: Prenadamedia Group.

Irwandi. 2010. Strategi Pembelajaran Biologi Berbasis Kontekstual. Bengkulu: Umb press

Jalaludin, 2009. Penggunaan Model Pembelajaran Berbasis Masalah dengan Pendekatan Inkuiri Terbimbing untuk Meningkatakan Penguasaan Konsep Listrik Dinamis dan Kecakapan ilamiah di SMA. Program Pasca Sarjana Pendidikan IPA Universitas Indonesia. Tesis. Bandung: Tidak diterbitkan.

Herlina, M. 2014. Perbedaan Penguasaan Konsep dan Kemamapuan Berpikir Kritis Mahasiswa mengunakan model Pembelajaran Search, Solve, And Share (SSCS) dengan Model Problem Base Instruction di Prodi Pendidikan Biologi FKIP UMB. Bengkulu. Tesis. Tidak diterbitkan 
Mudyahardjo, R. 2010. Pengantar Pendidikan. Jakarta: Rajawali Pers.

Pratiwi, Y.P. 2012. Pengaruh Model Pembelajaran Problem Based Learning terhadap Kemampuan Berpikir Kritis dan Berpikir Kreatif Siswa Pada Pembelajaran Biologi. Skripsi FKIP. Universitas Sebelas Maret. Surakarta.

Redhan. 2003. Meningkatkan Kemampuan Berpikir Kritis Siswa Melalui Pembelajaran Dengan Strategi Pemecahan Masalah. Universitas Negeri Singaraja.

Rusyana, A., Rustaman, Y. N. 2011. Pengembangan Program Perkuliahan Zoologi Invetebrata (P3ZI) Berbasis Keterampilan Berfikir Kritis. Bioedukasi Jurnal Biologi dan Pendidikan biologi 4(2): 1-8.

Sanjaya, W. 2011. Strategi Pembelajaran Berorientasi Standar Proses Pendidikan. Jakarta: Kencana Prenada Media.

Sanjaya, W. 2011. Perencananan dan Desain Sistem Pembelajaran. Jakarta: Penada Media Group.

Sumarni, W., Soepprodjo, \& Rahayu, K.P. 2009. Efektivitas Penerapan Metode Kasus Menggunakan Media Audiovisual Terhadap Hasil Belajar Kimia Siswa SMA. Jurnal Inovasi Pendidikan Kimia, 3 (1):345-353.
Trianto. 2011. Mendesain Model Pembelajaran Inovatifi-Progresif (Konsep, Landasan dan Implementasinya pada Kurikulum Tingkat Satuan Pendidikan (KTSP)). Jakarta: Prenada Media Group.

Trianto. 2010. Model Pembelajar Terpadu (Konsep Strategi dan Implementasinya dalam Kurikulum Tingkat Satuan Pendidikan (KTSP). Jakarta: Prenada Media Group.

Yamin, M. 2011. Paradigma Baru Pembelajaran. Jakarta: Gaung Persada.

Puspita, L., Suciati. dan Maridi. 2014. Pengaruh Model Problem Based Learning dengan Metode Eksperimen disertai Teknik Concept Map dan Mind Map Terhadap Prestasi Belajar Biologi ditinjau dari Motivasi Belajar dan Aktivitas Belajar Siswa. Jurnal Inkuiri . 3(I): 8595.

Yuliana, Tri . 2013. Perbedaan Penguasaan Konsep dan Keterampilan Proses Sains Melalui Pembelajaran Model Learning Cycle dan Inkuiri Terbimbing Pada Mata Pelajaran Biologi di SMP Negeri 2 Putri Hijau. Tesis. Program Pasca Sarjana Magister Pendidikan Biologi FKIP UMB. 